'Lung Patophysiology Department, National Tuberculosis and Lung Diseases Research Institute, Warsaw, Poland

${ }^{2} 3^{\text {rd }}$ Lung Diseases and Oncology Department, National Tuberculosis and Lung Diseases Research Institute, Warsaw, Poland

\title{
New spirometry? The 2019 update of the test standardization
}

\section{Introduction}

Spirometry is a commonly performed assessment of lung function for diagnostic purposes as well as for monitoring of chronic lung diseases. The last international standardization of this study was published in 2005 [1], and the Polish version of the recommendations appeared a year later [2]. After 14 years, a group of experts from two leading scientific societies, ATS (American Thoracic Society) and ERS (European Respiratory Society), published a joint position that updated the standardization of spirometry [3]. There are essentially no significant changes to the test technique, but there have been some modifications regarding the circumstances surrounding the test and the assessment of the maneuvers. Due to the short nature of this article, the reader will find below information on selected and, in the authors' opinion, the most important key changes compared to the standards being in use for the last 14 years.

\section{Contraindications for spirometry}

Spirometry is generally a safe procedure, as demonstrated by many years of experience and publications in the literature. Adverse events occur at a frequency of 5/10,000 and are usually mild (syncope was most commonly observed). The risk of adverse events in spirometry is primarily associated with significant fluctuations in chest pressures and their impact on the abdominal and thoracic organs, venous return and systemic blood pressure. Therefore, caution must be used for patients with medical conditions that could be adversely affected by these physiological consequences. The ATS/ERS recommendations on spirometry published at the end of 2019 give all contraindications with the status of "relative" and list the following situations requiring special attention (consider the appropriateness of performing the test):

- Due to increases in myocardial demand or changes in blood pressure

- Acute myocardial infarction within $1 \mathrm{wk}$

- Systemic hypotension or severe hypertension

- Significant atrial/ventricular arrhythmia

- Noncompensated heart failure

- Uncontrolled pulmonary hypertension

- Acute cor pulmonale

- Clinically unstable pulmonary embolism

- History of syncope related to forced expiration/cough

- Due to increases in intracranial/intraocular pressure

- Cerebral aneurysm

- Brain surgery within 4 wk

- Recent concussion with continuing symptoms

- Eye surgery within $1 \mathrm{wk}$

- Due to increases in sinus and middle ear pressures

- Sinus surgery or middle ear surgery or infection within $1 \mathrm{wk}$

- Due to increases in intrathoracic and intraabdominal pressure

- Presence of pneumothorax

- Thoracic surgery within $4 \mathrm{wk}$

- Abdominal surgery within $4 \mathrm{wk}$

- Late-term pregnancy

Address for correspondence: Piotr W Boros, Lung Patophysiology Department, National Research Institute of Tuberculosis and Lung Diseases, Warsaw, Poland; e-mail: piotr.boros@gmil.com

DOI: 10.5603/ARM.2020.0082

Received: 26.02 .2020

Copyright (C) 2020 PTChP

ISSN 2451-4934 
- Infection control issues

- Active or suspected transmissible respiratory or systemic infection, including tuberculosis

- Physical conditions predisposing to transmission of infections, such as hemoptysis, significant secretions, oral lesions or oral bleeding.

It is worth noting that the presence of aortic aneurysms has ceased to be a contraindication. Spirometry should always be interrupted if pain occurs during maneuvers. Relative contraindications do not exclude the possibility of spirometry, but they should be taken into account when referring the patient to this examination. Individuals with potential contraindications that would prevent an examination in primary care settings may be examined in more experienced centers and with the access to emergency care. The decision to perform spirometry is determined by the referring physician based on a risk and benefit assessment for the individual patient. Potential contraindications should be provided on the referral form.

\section{Equipment requirements}

The most important change was adapting the standards to the requirements of the International Organization for Standardization (ISO) standard number 26782 dated 2009, replacing the ATS standard curves with curves according to the mentioned requirements and narrowing the accuracy range to $\pm 2.5 \%$ in both: testing the spirometer using standard curves as well as checking calibration using a 3-liter calibration syringe. Information was also added about the required accuracy of the $3 \mathrm{~L}$ calibration syringe, which should be within $\pm 0.5 \%$, what in practice gives the accuracy of the entire calibration process at the current recommended level of $\pm 3 \%$. Recommendations for daily checking/performing calibration indicate the need for maneuvers in a wide range of flows (from 0.5 to $12 \mathrm{~L} / \mathrm{s}$, i.e. piston movement lasting from 0.5 to $6 \mathrm{sec}$ ), which in practice also means checking the so-called linearity. It is also recommended to periodically check the calibration syringe for accuracy and monthly leak test.

\section{Personnel qualifications}

The relationship between the commitment and skills of the researcher and the quality of spirometry are emphasized. It is the responsibility of the person performing the study to observe the patient and interact with him in order to achieve optimal results. This requires a combination of skills acquired during training and experience that comes with the time and number of performed tests.

\section{Patient's data}

It is obvious that the correct person's anthropometric data should be obtained and, for this purpose, appropriate height and weight measurements taken. Current standards specify the degree of accuracy for individual values (age and height to 1 decimal place, weight to the nearest $0.5 \mathrm{~kg}$ ). Gender and belonging to an ethnic group at birth, not declared by the patient, should be used to calculate predicted values. In the absence of these data, the person interpreting the result should be notified. The list of behaviors to be avoided before spirometry testing was modified: smoking electronic cigarettes (vaping) and consumption of intoxicants (to avoid problems with coordination, understanding and physical performance) were added.

\section{Spirometry measurements}

Values of $\mathrm{FEV}_{1}$ (forced expiratory volume at the first second of exhalation), FVC (forced vital capacity) and their ratio $\mathrm{FEV}_{1} / \mathrm{FVC}$ expressed as a fraction (or less correctly as a percentage) called the Tiffeneau index still remain crucial for the spirometry test result. However, it is worth noting that the current standards also indicate an important role (and recommend performing) of the measurement of the FIVC (forced inspiratory vital capacity) maneuver after the FVC maneuver in order to verify the correctness of the inspiration preceding the forced exhalation. For this reason, spirometers measuring only expiratory volumes (in practice no longer employed) should not be used.

An important change is the redefinition of a technically correct (acceptable) forced expiration maneuver and the associated introduction of the concept of a maneuver technically unacceptable but clinically useful.

A forced expiratory maneuver is considered as technically correct if the following criteria are met:

- sufficiently fast onset of exhalation as indicated by BEV (back extrapolated volume) $<5 \%$ of FVC or $<100 \mathrm{~mL}$, whichever is greater;

- no artifacts (e.g. coughing, closing the glottis, incomplete breathing effort);

- one of the criteria for successful completion of the maneuver was achieved in the following hierarchy: 
Table 1. Grading System for FEV 1 and FVC (graded separately)

\begin{tabular}{lccc}
\hline Grade & Number of measurements & $\begin{array}{c}\text { Repeatability: } \\
\text { Age }>\mathbf{6} \text { years }\end{array}$ & $\begin{array}{c}\text { Repeatability: } \\
\text { Age } \leq \mathbf{6} \text { years }\end{array}$ \\
\hline$A$ & $\geq 3$ acceptable & $\leq 0.15 \mathrm{~L}$ & $\leq 0.1 \mathrm{~L}^{*}$ \\
$\mathrm{~B}$ & 2 acceptable & $\leq 0.15 \mathrm{~L}$ & $\leq 0.1 \mathrm{~L}^{*}$ \\
C & $\geq 2$ acceptable & $\leq 0.2 \mathrm{~L}$ & $\leq 0.15 \mathrm{~L}^{*}$ \\
D & $\geq 2$ acceptable & $\leq 0.25 \mathrm{~L}$ & $\leq 0.2 \mathrm{~L}^{*}$ \\
E & $\geq 2$ acceptable & $>0.25 \mathrm{~L}$ & $>0.2 \mathrm{~L}^{*}$ \\
& OR 1 acceptable & $\mathrm{N} / \mathrm{A}$ & $\mathrm{N} / \mathrm{A}$ \\
$\mathrm{H}$ & 0 acceptable AND $\geq 1$ usable & $\mathrm{N} / \mathrm{A}$ & $\mathrm{N} / \mathrm{A}$ \\
\hline
\end{tabular}

${ }^{*}$ Or $10 \%$ of the highest value, whichever is greater; applies for age 6 years or younger only. FEV $_{1}$ — forced expiratory volume at the first second of exhalation; FVC forced vital capacity; N/A - not applicable

- a plateau was reached on the volume-time curve (volume change at last second exhalation $<25 \mathrm{~mL}$ );

- exhalation continuously lasted 15 seconds;

- satisfactory FVC repeatability has been obtained or the FVC measured last is bigger than the best so far (in the same session).

If FIVC is correctly recorded, then the inspiratory - expiratory differences (FIVC - FVC) should not be greater than $100 \mathrm{~mL}$ or $5 \%$ of FVC. If satisfactory reproducibility is not achieved (the differences between the 2 best FVC and $\mathrm{FEV}_{1}$ results exceed $150 \mathrm{ml}$ ), it is recommended to repeat maneuvers, but no more than 8 forced exhalations should be performed during one measurement session.

It is worth noting that there is no longer striving for a minimum of 6 seconds of exhalation in cases where a plateau of the volume-time expiratory curve is previously reached. The recommendations also mention about the time to reach PEF (peak expiratory flow), which should be as short as possible and usually should not exceed $0.15 \mathrm{sec}$, but this is not a mandatory criterion.

The "U" category has been added to the previously slightly modified thresholds of acceptable repeatability [4] - a useful result but not meeting the technical acceptability criteria. To simplify, these are maneuvers during which there is no doubt about the correct start, but none of the conditions for successful completion can be achieved. Interpretation of such results is possible but has limited value, especially in the case of results in the abnormal range. A new scale was introduced regarding the quality of the spirometry test from the point of view of the degree of repeatability of results (A, B, C, D, E, U, F), in which FEV ${ }_{1}$ and FVC measurements are assessed separately (Table 1) [3].

\section{Bronchodilator responsiveness testing}

The need to distinguish the concepts of reversibility of obstruction (defined as normalization of the $\mathrm{FEV}_{1} / \mathrm{FVC}$ ratio) from the significance of improvement (assessed as response in the $\mathrm{FEV}_{1}$ or FVC) and the necessity to unify the nomenclature in this area were pointed out. The list of drugs and the recommended time periods for which they should be discontinued before the test to check the reactivity of the airways to the bronchodilator have been updated. For drugs from the ultra-long-acting beta2-agonist group (e.g. indacaterol, vilanterol, olodaterol), the recommended time since the last dose is 36 hours, for long-acting muscarinic receptor antagonist (e.g. tiotropium, umeclidinium, aclidinium or glycopyronium), delay should be a bit longer, approx. 36-48 hours. It is worth noting that these periods are shorter than when preparing for methacholine challenge test because the protective effect of these drugs lasts longer than the bronchodilation effect.

There is also a recommendation that the first spirometry test performed for diagnostic purposes should always be accompanied by bronchodilator responsiveness testing because the lack of airway obstruction in the baseline does not exclude possible significant improvement after bronchodilators. The recommendation seems to be justified from a purely substantive point of view, but the authors' experience shows that the "reversibility test" should not be the first spirometry in the subject's life because the effect of the drug may be superimposed on the learning effect and the improvement observed may be the result of a better technique rather than the effect of the real bronchodilation. 


\section{Conflict of interest}

The authors have no conflict of interest related to the subject matter.

\section{References:}

1. Miller MR, Hankinson J, Brusasco V, et al. Standardisation of spirometry. Eur Respir J. 2005; 26(2): 319-338, doi: 10.1183/09031936.05.00034805, indexed in Pubmed: 16055882
2. Zalecenia Polskiego Towarzystwa Chorób Płuc dotyczące wykonywania badań spirometrycznych. Pneumonol Alergol Pol. 2006; 74: 2-44.

3. Graham BL, Steenbruggen I, Miller MR, et al. Standardization of spirometry 2019 update. An official American Thoracic Society and European Respiratory Society technical statement. Am J Respir Crit Care Med. 2019; 200(8): e70-e88, doi: 10.1164/rccm.201908-1590ST, indexed in Pubmed: 31613151.

4. Culver BH, Graham BL, Coates AL, et al. Recommendations for a standardized pulmonary function report. An official American Thoracic Society technical statement. Am J Respir Crit Care Med. 2017; 196(11): 1463-1472, doi: 10.1164/rccm. 201710-1981ST, indexed in Pubmed: 29192835. 